\title{
Increasing the Solubility Limit for Tetrahedral Aluminium in ZnO:Al Nanorods by Variation in Synthesis Parameters
}

\author{
Anke Kelchtermans, ${ }^{1}$ Peter Adriaensens, ${ }^{2}$ Daniel Slocombe, ${ }^{3}$ \\ Vladimir L. Kuznetsov, ${ }^{3}$ Joke Hadermann, ${ }^{4}$ Alexander Riskin, ${ }^{1}$ Ken Elen, ${ }^{1,5}$ \\ Peter P. Edwards, ${ }^{3}$ An Hardy, ${ }^{1,5}$ and Marlies K. Van Bael ${ }^{1,5}$ \\ ${ }^{1}$ Inorganic and Physical Chemistry, Institute for Materials Research, Hasselt University, Agoralaan Building D, \\ 3590 Diepenbeek, Belgium \\ ${ }^{2}$ Applied and Analytical Chemistry, Institute for Materials Research, Hasselt University, Agoralaan Building D, \\ 3590 Diepenbeek, Belgium \\ ${ }^{3}$ Department of Chemistry, Inorganic Chemistry Laboratory, University of Oxford, South Parks Road, Oxford OX1 3QR, UK \\ ${ }^{4}$ EMAT, University of Antwerp, 2020 Antwerp, Belgium \\ ${ }^{5}$ Division IMOMEC, IMEC vzw, Agoralaan Building D, 3590 Diepenbeek, Belgium
}

Correspondence should be addressed to Marlies K. Van Bael; marlies.vanbael@uhasselt.be

Received 2 December 2014; Revised 20 January 2015; Accepted 20 January 2015

Academic Editor: Neeraj Dwivedi

Copyright (C) 2015 Anke Kelchtermans et al. This is an open access article distributed under the Creative Commons Attribution License, which permits unrestricted use, distribution, and reproduction in any medium, provided the original work is properly cited.

\begin{abstract}
Nanocrystalline ZnO:Al nanoparticles are suitable building blocks for transparent conductive layers. As the concentration of substitutional tetrahedral $\mathrm{Al}$ is an important factor for improving conductivity, here we aim to increase the fraction of substitutional $\mathrm{Al}$. To this end, synthesis parameters of a solvothermal reaction yielding $\mathrm{ZnO}: \mathrm{Al}$ nanorods were varied. A unique set of complementary techniques was combined to reveal the exact position of the aluminium ions in the $\mathrm{ZnO}$ lattice and demonstrated its importance in order to evaluate the potential of $\mathrm{ZnO}$ : Al nanocrystals as optimal building blocks for solution deposited transparent conductive oxide layers. Both an extension of the solvothermal reaction time and stirring during solvothermal treatment result in a higher total tetrahedral aluminium content in the $\mathrm{ZnO}$ lattice. However, only the longer solvothermal treatment effectively results in an increase of the substitutional positions aimed for.
\end{abstract}

\section{Introduction}

Because of the coexistence of high conductivity and high transparency in the visible region, the realization of transparent conductive oxides (TCOs) has attracted much interest for optoelectronic device applications, such as solar cells and displays [1-3]. Among all TCOs, Al-doped $\mathrm{ZnO}$ ( $\mathrm{ZnO}: \mathrm{Al}$ ) has gained considerable and continuous interest as it represents a lower-cost, earth-abundant alternative to the widely used TCO indium tin oxide (ITO) [4]. At the same time, TCO nanocrystals (NCs) have recently drawn attention because of their low cost associated with the possibility of solution processing and the potential to exploit their size-dependent properties [5]. Deposition of colloidal TCO NCs as a nanoink is highly appealing for integration into emerging flexible electronics, such as displays, electronic paper, or solar cells $[6,7]$. While the synthesis of $\mathrm{ZnO}$ :Al nanocrystals and films has recently advanced markedly, it still remains a challenge to control dopant incorporation in zinc oxide based TCO NCs [8-16]. Even more, probing doping efficiency and understanding whether or not dopants have substituted the desired host atoms are not trivial. No single analytical tool is fully satisfactory in this regard. Instead, an appropriate combination of characterization techniques can give more reliable insights. Identifying, understanding and ultimately controlling the uptake, dopant content and dopant location in inorganic nanostructures is as an important goal. First, the overall solubility limit of $\mathrm{Al}$ in the $\mathrm{ZnO}$ lattice is rather low. The thermodynamic solubility limit of $\mathrm{Al}$ in $\mathrm{ZnO}$ thin films is in the range of $1-2 \%$. An experimental solubility limit has 
been estimated under 0.3 at\% of $\mathrm{Al}$ using X-ray diffraction refinements, whereas NMR analyses lead rather to a limit well below 0.1 at $\%[17,18]$. Furthermore, it is believed that only when the dopants occupy substitutional tetrahedral sites in the $\mathrm{ZnO}$ crystal lattice, shallow donor levels are created which allow promotion of free carriers into the conduction band [19-21]. Besides the substitutional tetrahedral position, the aluminium ions can also occupy empty interstitial tetrahedral and octahedral sites in the hexagonal wurtzite structure of $\mathrm{ZnO}$. In these positions however, they will act as an acceptor, hence decreasing the conductivity $[18,20,22]$.

Previous work [23] demonstrated the existence of a constant, synthesis-dependent solubility limit for tetrahedral aluminium in two series of $\mathrm{ZnO}: \mathrm{Al}$ nanoparticles. For the nanoequiaxed particles 0.25 at $\%$ of $\mathrm{Al}$ is placed in tetrahedral positions, which is five times higher compared with the nanorod particles, where only 0.05 at $\%$ of $\mathrm{Al}$ is placed in tetrahedral positions. The aim of the work presented in this paper is to study the synthesis parameters in order to increase the tetrahedral aluminium content in the nanorods. More specifically, the substitutional tetrahedral aluminium content, accountable for the increased conductivity, is targeted.

\section{Experimental}

2.1. Materials. Zinc acetylacetonate hydrate $\mathrm{Zn}(\mathrm{acac})_{2} \cdot x \mathrm{H}_{2} \mathrm{O}$ (Sigma-Aldrich), aluminium acetylacetonate $\mathrm{Al}(\mathrm{acac})_{3}(99 \%$, Sigma-Aldrich), and benzyl alcohol $\mathrm{C}_{6} \mathrm{H}_{5} \mathrm{CH}_{2} \mathrm{OH}$ (99\%, Alfa Aesar) are used as received. The amount of hydrate water $(x)$ in the zinc acetylacetonate hydrate is verified by high-resolution thermogravimetric analysis (HR-TGA) and inductively coupled plasma atomic emission spectroscopy (ICP-AES) to be 1 per formula unit.

2.2. Synthesis of the $\mathrm{ZnO}: \mathrm{Al}$ Nanorods. A mixture of $1 \mathrm{~g}$ $\mathrm{Zn}(\mathrm{acac})_{2} \cdot 1 \mathrm{H}_{2} \mathrm{O}, 0.057 \mathrm{~g} \mathrm{Al}(\mathrm{acac})_{3}(0.5 \mathrm{~mol} \%$ with respect to $\mathrm{Zn}$ ), and $40 \mathrm{~mL}$ benzyl alcohol is stirred for 30 minutes in a Teflon liner (inner volume of $80 \mathrm{~mL}$ ). This Teflon liner is then transferred into a stainless steel vessel which is sealed and placed in a preheated furnace at $200^{\circ} \mathrm{C}$ for $6 \mathrm{~h}$. After cooling down to room temperature, the resulting precipitate is centrifuged ( $4400 \mathrm{rpm}, 45^{\prime}$ ), washed (with methanol and milliQ water), and dried [23]. As a variation in synthesis parameters, the time the autoclave stays in the furnace is extended to $48 \mathrm{~h}$ and $96 \mathrm{~h}$, respectively. Another variation in the synthesis parameters is the use of a solvothermal reactor (PARR 5500 series compact reactor) with stirring option instead of a furnace to treat the reaction mixture.

2.3. Characterization. The crystal phase of the dry nanopowders was determined at room temperature by X-ray diffraction (XRD) in the $2 \theta$ range from 10 to $60^{\circ}$, using a Siemens $\mathrm{D}-5000$ diffractometer with $\mathrm{Cu} \mathrm{K} \alpha 1$ radiation. The size and morphology of the $\mathrm{ZnO}$ (:Al) nanocrystals were characterized with transmission electron microscopy (TEM), carried out on a FEI Tecnai Spirit at an acceleration voltage of $120 \mathrm{kV}$. For this purpose, a small drop of powdered sample redispersed in methanol was deposited on a carbon-film coated copper grid and dried under an infrared lamp. The structure of the nanocrystals at the atomic scale was characterized using high resolution transmission electron microscopy (HR-TEM) performed on a Fei Tecnai G2, operated at $200 \mathrm{kV}$. Samples for HR-TEM were prepared by redispersing the powder in ethanol using an ultrasonic bath for 10 minutes and then depositing a few drops of this dispersion onto a holey carbon grid.

The ${ }^{27} \mathrm{Al}$ solid-state magic angle spinning nuclear magnetic resonance (MAS-NMR) measurements were performed at room temperature on an Agilent VNMRS $400 \mathrm{MHz}$ spectrometer ( $9.4 T$ wide bore magnet) equipped with a VarianChemagnetics T3HX $3.2 \mathrm{~mm}$ probe. The resonance frequency of the aluminum nuclei is $104.22 \mathrm{MHz}$. The samples were packed into a $3.2 \mathrm{~mm}$ zirconia rotor and sealed with tight fitting Torlon caps. The spectra were obtained at a rotor spinning rate of $18 \mathrm{kHz}$ by using a single pulse experiment with a $\pi / 2$ pulse of $4.2 \mu \mathrm{s}$, an acquisition time of $10 \mathrm{~ms}$, a preparation delay of $6 \mathrm{~s}$, and a spectral width of $100 \mathrm{kHz}$. The number of accumulations was around 20000. The chemical shift scale, in parts per million (ppm), was externally referenced to $\mathrm{AlCl}_{3} \cdot 6 \mathrm{H}_{2} \mathrm{O}$ at $0 \mathrm{ppm}$. The aluminum $T_{1}$ relaxation decay times were measured on the same spectrometer via the inversion recovery method in which the evolution time $t$ (19 values) was varied between $0.5 \mathrm{~ms}$ and $30 \mathrm{~s}$. The repetition delay was set to $20 \mathrm{~s}$ and about 900 scans were accumulated. The integrated signal intensity $I(t)$ of the tetrahedral resonance was analyzed biexponentially as a function of the variable recovery time $t$ according to

$$
\begin{aligned}
I(t)= & I_{o}^{S} \cdot\left(1-2 \cdot \exp \left(\frac{t}{T_{1 \mathrm{H}}^{S}}\right)\right) \\
& +I_{o}^{L} \cdot\left(1-2 \cdot \exp \left(-\frac{t}{T_{1 \mathrm{H}}^{L}}\right)\right)+c^{\mathrm{te}} .
\end{aligned}
$$

The superscripts $S$ and $L$ refer to the fractions with short and long decay time, respectively.

Transmission Fourier transform infrared (FT-IR) spectra were recorded at room temperature using a Vertex 70 FTIR spectrometer from Bruker Optics. The transmittance of $\mathrm{KBr}$ pellets containing $0.5 \mathrm{wt} \% \mathrm{ZnO}(\mathrm{Al})$ was measured in the wavenumber interval of $4000-400 \mathrm{~cm}^{-1}$. The resolution of the spectra is $4 \mathrm{~cm}^{-1}$.

A resonant microwave cavity perturbation method was used to measure the microwave conductivity of the powders [24]. Low dielectric loss quartz tubes (1.6 $\mathrm{mm}$ inner diameter) containing powder samples were inserted axially into an aluminum $\mathrm{TM}_{010}$ mode cylindrical resonant cavity. The cavity has a height of $40 \mathrm{~mm}$ and a $46 \mathrm{~mm}$ radius, with a corresponding operating frequency of $2.45 \mathrm{GHz}$ and an unloaded quality factor of over 8000. $\mathrm{S}_{21}$ measurements were taken using an Agilent E5071B vector network analyzer. Further experimental details are described in [25].

\section{Results and Discussion}

In the XRD patterns (Figure 1) of the $\mathrm{Al}$-doped $\mathrm{ZnO}$ nanocrystals, solvothermally synthesized for, respectively, 


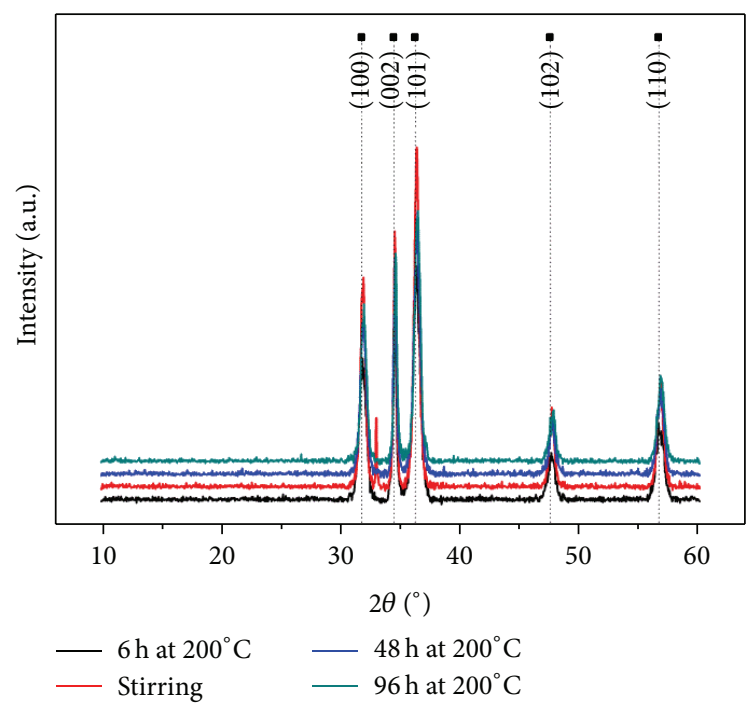

FIGURE 1: XRD patterns of Al-doped $\mathrm{ZnO}$ nanocrystalline rods as a function of the solvothermal reaction time and presence of solvothermal stirring $\left(6 \mathrm{~h}\right.$ at $\left.200^{\circ} \mathrm{C}\right)$.

$6 \mathrm{~h}, 48 \mathrm{~h}$, and $96 \mathrm{~h}$ at $200^{\circ} \mathrm{C}$ without stirring and solvothermally treated for $6 \mathrm{~h}$ at $200^{\circ} \mathrm{C}$ with stirring, the peaks are identified as (100), (002), (101), (102), and (110) reflections of the hexagonal wurtzite structure of $\mathrm{ZnO}$ (JCPDS 36-1451), confirming that all the $\mathrm{ZnO}$ :Al nanocrystals retain the similar $\mathrm{ZnO}$ structure. The sharp signal at $32.9^{\circ}$ in the pattern after stirring originates from the Si sample holder.

TEM characterization (Figure 2) reveals that despite the extension of the reaction time or stirring during the solvothermal treatment, the morphology of the crystalline Al-doped $\mathrm{ZnO}$ nanorods does not change. Possible differences in the position of the aluminium ion in the $\mathrm{ZnO}$ lattice can be evaluated by means of ${ }^{27} \mathrm{Al}-\mathrm{NMR}$ measurements (Figure 3), from which it is possible to distinguish between tetrahedral (75 \pm 15 ppm [26]) and octahedral (0-20 ppm [26]) coordination of aluminium. Both the signal corresponding to aluminium in a 4-fold coordination with oxygen (tetrahedral) and the signal corresponding to aluminium in a 6 -fold coordination with oxygen (octahedral) have a rather sharp line shape, indicating that the $\mathrm{Al}$ resides in a highly ordered, symmetrical crystalline environment. The absence of broad resonance signals, observed by Kemmitt et al. [20], indicates that no amorphous phase of $\mathrm{Al}$-doped $\mathrm{ZnO}$ is present. The spectra clearly reveal an increase in tetrahedral aluminium content as a function of the solvothermal reaction time. Associated with an extension of the solvothermal treatment time from $6 \mathrm{~h}$ to, respectively, $48 \mathrm{~h}$ and $96 \mathrm{~h}$, the tetrahedral aluminium fraction increases from 15\% (Figure 3(a)) to, respectively, 27\% (Figure 3(b)) and $31 \%$ (Figure 3(c)). However, by stirring the reaction mixture during the solvothermal treatment $(6 \mathrm{~h})$, this tetrahedral fraction even increases up to $41 \%$ (Figure 3(d)). Although the spectra show a significant increase of the tetrahedral aluminium content, this is not necessarily associated with a higher amount of the desired tetrahedral substitutional aluminium, leading to an increased conductivity as 4-fold coordinated aluminium can appear in substitutional as well as interstitial positions in the $\mathrm{ZnO}$ lattice. To obtain more detailed information regarding this distribution, FTIR is used as a complementary technique. FTIR is able to detect surface plasmon resonance effects due to the presence of free charge carriers, providing an indirect proof for substitutional doping [27-29]. The spectrum (Figure 4) of the $\mathrm{ZnO}: \mathrm{Al}$ nanorods $(0.5 \% \mathrm{Al})$ that were solvothermally treated for $6 \mathrm{~h}$ exhibits the same features as the spectrum of ordinary $\mathrm{ZnO}$. The broad absorption bands at $\sim 3430 \mathrm{~cm}^{-1}$ and $\sim 1645 \mathrm{~cm}^{-1}$ encompass the $\mathrm{O}-\mathrm{H}$ stretching vibrations of adsorbed water on the $\mathrm{ZnO}: \mathrm{Al}$ surface while the strong absorption band between 500 and $400 \mathrm{~cm}^{-1}$ can be attributed to the stretching modes of $\mathrm{Zn}-\mathrm{O}$ and/or $\mathrm{Al}-\mathrm{O}$. The spectra of the $\mathrm{ZnO}: \mathrm{Al}$ nanorods obtained after longer solvothermal reaction times $(48 \mathrm{~h}$ and $96 \mathrm{~h}$ ) on the other hand exhibit a broad additional absorption band between 600 and $3000 \mathrm{~cm}^{-1}$ which can be attributed to surface plasmon IR absorptions originating from free charge carriers. It is clear that longer solvothermal treatments lead to more pronounced plasmon resonance absorptions, which in turn can be related to a higher charge carrier concentration in these particles [30, 31]. It is assumed that only substitutional $\mathrm{Al}$ contributes to the formation of charge carriers. This leads to the conclusion that a longer solvothermal reaction time leads to a higher content of substitutional aluminium, which should be beneficial for the conductivity [20,21]. In contrast to these findings, the even higher content of tetrahedral aluminium obtained by stirring during solvothermal treatment does not result in more free charge carriers. The relatively high $(41 \%)$ content of tetrahedral aluminium as determined by ${ }^{27} \mathrm{Al}-\mathrm{NMR}$ (Figure 3(d)) is clearly not correlated to an increase of free charge carriers as no distinct plasma resonance IR absorption is observed (Figure 4). The coexistence of high tetrahedral aluminium content and a low number of free charge carriers indicates that most of the aluminium ions have to be located in interstitial tetrahedral positions. A possible explanation might be a conflict between thermodynamics and kinetics; that is, stirring promotes the tetrahedral aluminium incorporation but the limited reaction time of $6 \mathrm{~h}$ does not allow reaching thermodynamic equilibrium. Further, the different setups (autoclave in furnace and solvothermal reactor) might result in a different heating profile and probably different heating rate, which could also influence the dopant position [20].

In addition to FTIR characterization, relative conductivity values were determined for the different powders by microwave resonant perturbation measurements. By placing the sample in a resonant microwave electric field, the shift in resonant bandwidth $\Delta \mathrm{BW}$ can be directly related to the conductivity of the powders since the imaginary part of the permittivity $\varepsilon^{\prime \prime}$ is dominated by the conductivity $\sigma$ for conductive samples according to $\varepsilon^{\prime \prime}=\sigma / \varepsilon_{0} \omega$, where $\varepsilon_{0}$ is the permittivity of free space and $\omega$ is the angular frequency. The measured $\triangle \mathrm{BW}$ is proportional to $\varepsilon^{\prime \prime}$ and thus to $\sigma$ for a given frequency. Although this technique does not provide the absolute value of the electrical conductivity, it allows us to rank different $\mathrm{ZnO}$ :Al particle samples according to their 

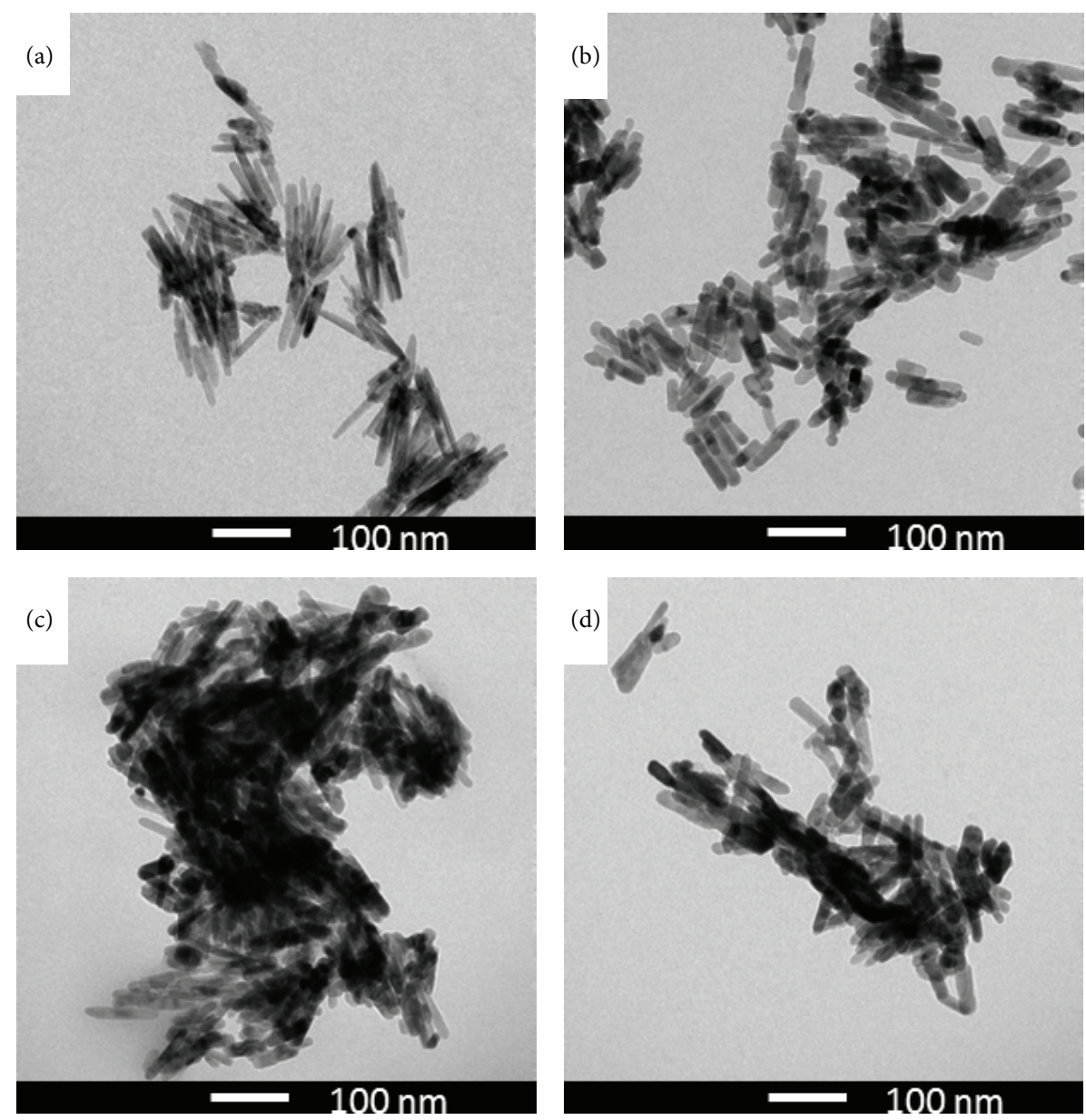

Figure 2: TEM images of the $\mathrm{ZnO}$ : $\mathrm{Al}$ nanorods solvothermally treated for $6 \mathrm{~h}$ at $200^{\circ} \mathrm{C}$ (a), solvothermally treated for $6 \mathrm{~h}$ at $200^{\circ} \mathrm{C}$ while

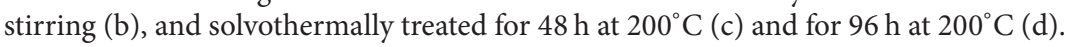

TABLE 1: $T_{1}$ spin-lattice relaxation times with their corresponding fractions ( $\%$ of total amount of tetrahedral Al) observed for the tetrahedrally coordinated $\mathrm{Al}$ of the $\mathrm{ZnO}: \mathrm{Al}$ powders obtained after a solvothermal treatment of $96 \mathrm{~h}$ and after stirring during $6 \mathrm{~h}$ solvothermal treatment.

\begin{tabular}{|c|c|c|c|c|}
\hline & \multicolumn{2}{|c|}{$96 \mathrm{~h} @ 200^{\circ} \mathrm{C}$ without stirring } & \multicolumn{2}{|c|}{$6 \mathrm{~h} @ 200^{\circ} \mathrm{C}$ with stirring } \\
\hline & $T_{1}$ relaxation time $(\mathrm{ms})$ & Fraction & $T_{1}$ relaxation time $(\mathrm{ms})$ & Fraction \\
\hline Interstitial tetrahedral $\mathrm{Al}$ & 4.6 & $23 \%$ & 24.8 & $34 \%$ \\
\hline Substitutional tetrahedral Al & 808 & $77 \%$ & 725 & $66 \%$ \\
\hline
\end{tabular}

electrical conductivity. Effective medium theory may be used to infer the absolute dielectric properties of powders, though here the measured "effective" values indicate the relative conductivity of each powder. The microwave absorption data (Figure 5) show a significant increase in $\triangle \mathrm{BW}$ or electrical conductivity for longer solvothermal treatments, supporting the FTIR data which indicated a higher number of free charge carriers. On the other hand, the $\mathrm{ZnO}$ : Al nanocrystals obtained by stirring during the solvothermal treatment do not exhibit a significant increase in electrical conductivity, also in accordance with the lack of a surface plasmon absorption signal in the FTIR spectrum.

The indirect indications for the exact aluminium position, determined by FTIR and microwave absorption measurements, were ultimately confirmed by evaluating the $T_{1}$ spin-lattice relaxation decay time behavior of the tetrahedral Al (signal at $\pm 80 \mathrm{ppm}$ ). Based on the ${ }^{27} \mathrm{Al}-\mathrm{NMR}$ spectra (Figure 3) a first distinction between aluminium in an octahedral or tetrahedral coordination with oxygen could be made. By focusing now on the tetrahedral signal and monitoring the $T_{1}$ spin-lattice relaxation decay time of this signal, one can distinguish between aluminium in differently ordered tetrahedral environments. For $\mathrm{ZnO}: \mathrm{Al}$ nanocrystals which were solvothermally treated for $96 \mathrm{~h}$ as well as for $\mathrm{ZnO}: \mathrm{Al}$ nanocrystals obtained by stirring during their $6 \mathrm{~h}$ solvothermal treatment, two ${ }^{27} \mathrm{Al}$ spin populations (fractions) with a different $T_{1}$ relaxation decay time were observed (Table 1), indicating the existence of two different tetrahedral environments. 


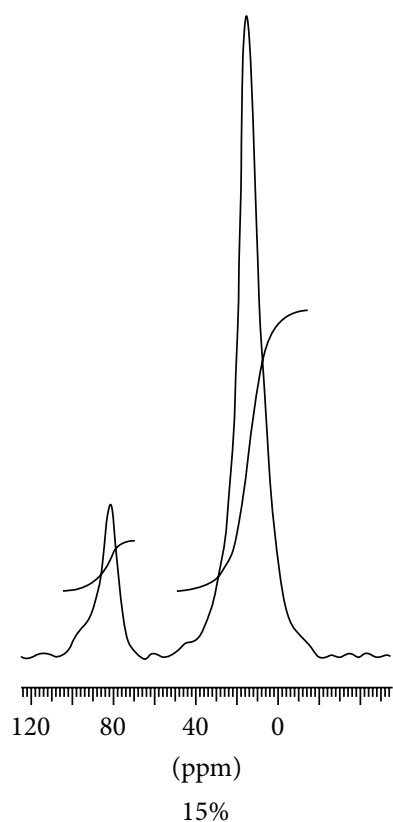

(a)

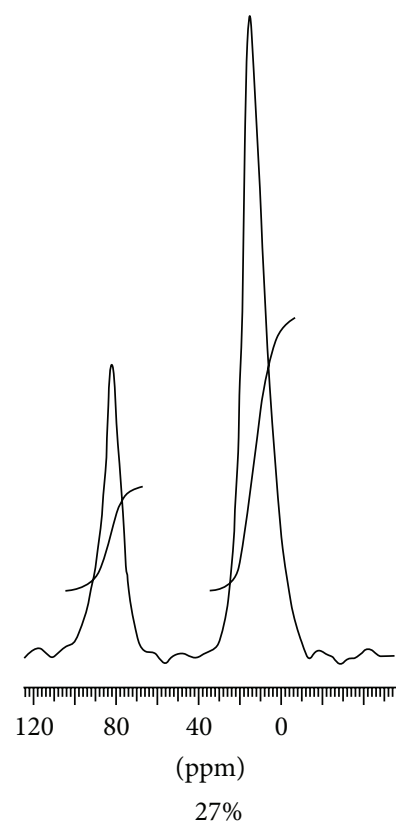

(b)

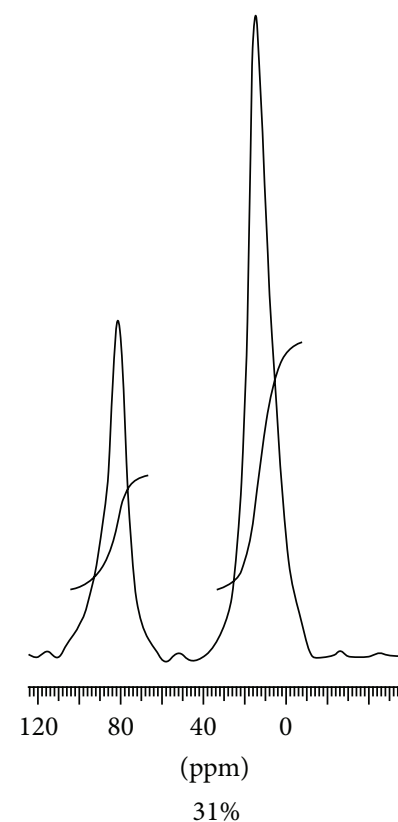

(c)

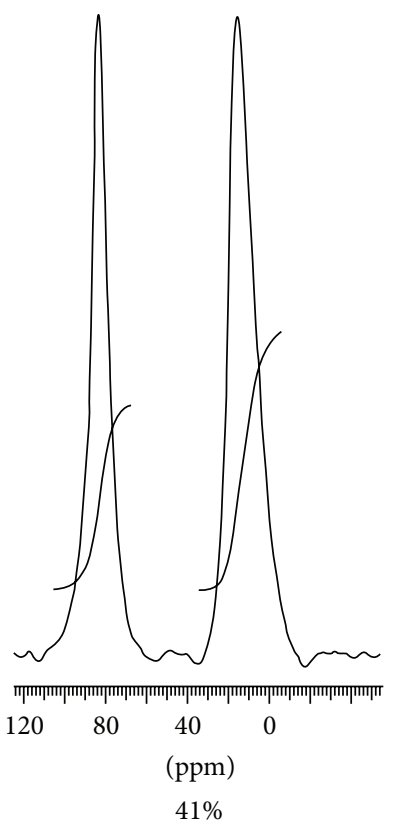

(d)

FIGURE 3: Al-NMR spectra (with integral lines) of the $\mathrm{ZnO}: \mathrm{Al}$ nanorods solvothermally treated at $200^{\circ} \mathrm{C}$ for $6 \mathrm{~h}$ (a), $48 \mathrm{~h}$ (b), $96 \mathrm{~h}$ (c), and for $6 \mathrm{~h}$ at $200^{\circ} \mathrm{C}$ while stirring (d). The percentages below the Al-NMR spectra express the respective amount of aluminium in tetrahedral position.

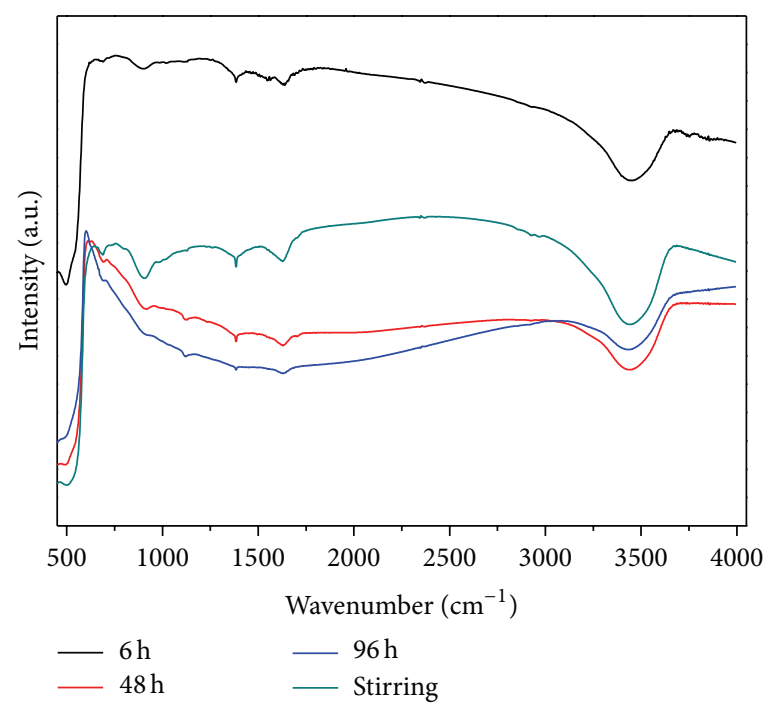

FIGURE 4: FT-IR spectra of the different $\mathrm{ZnO}: \mathrm{Al}$ nanorods.

For the nanorods obtained after a $96 \mathrm{~h}$ solvothermal treatment, $77 \%$ of the tetrahedral aluminium has a long spin-lattice relaxation time of $\pm 0.8 \mathrm{~s}$ against $66 \%\left(T_{1}=\right.$ $\pm 0.7 \mathrm{~s}$ ) in the $\mathrm{ZnO}$ :Al nanorods obtained by stirring during solvothermal treatment. In general, sharp signals in the ${ }^{27} \mathrm{Al}-$ NMR spectrum, corresponding with aluminium located in a highly ordered, symmetrical crystalline environment, exhibit relatively long spin-lattice relaxation times. Following this trend, the relatively long $T_{1}$ decay time (or slow spin-lattice relaxation rate) is associated with tetrahedral aluminium in substitutional positions $[32,33]$. The higher fraction of tetrahedral substitutional aluminium in the $\mathrm{ZnO}: \mathrm{Al}$ nanorods which were obtained after treatment for $96 \mathrm{~h}$ at $200^{\circ} \mathrm{C}$ supports the indirect indications obtained from the FTIR and microwave absorption measurements. Regarding the short $T_{1}$ spin-lattice relaxation time of the tetrahedral signal, 23\% of the tetrahedral $\mathrm{Al}$ in the rods obtained after a solvothermal treatment of $96 \mathrm{~h}$ at $200^{\circ} \mathrm{C}$ has a $T_{1}=4.6 \mathrm{~ms}$ while $34 \%$ of the tetrahedral $\mathrm{Al}$ in the rods obtained after solvothermal treatment while stirring $(6 \mathrm{~h})$ has a $T_{1}$ of $24.8 \mathrm{~ms}$. The $T_{1}$ 


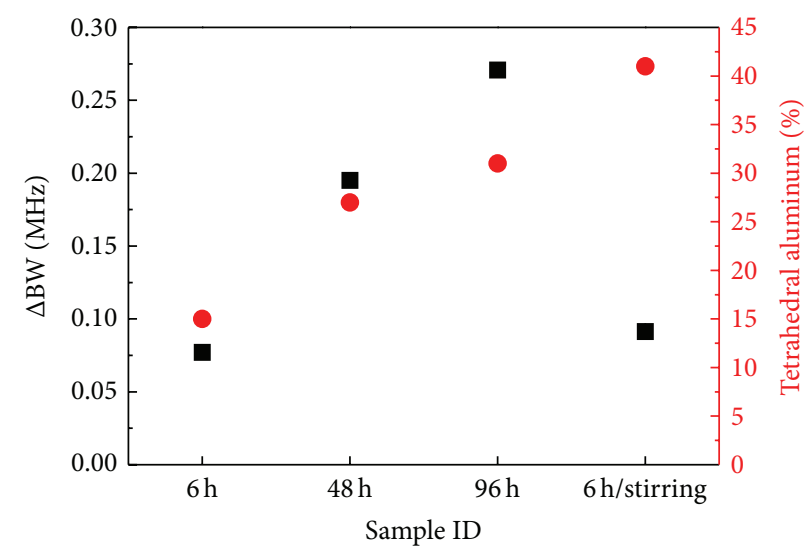

Figure 5: Microwave absorption data of the different $\mathrm{ZnO}$ :Al samples.



(a)

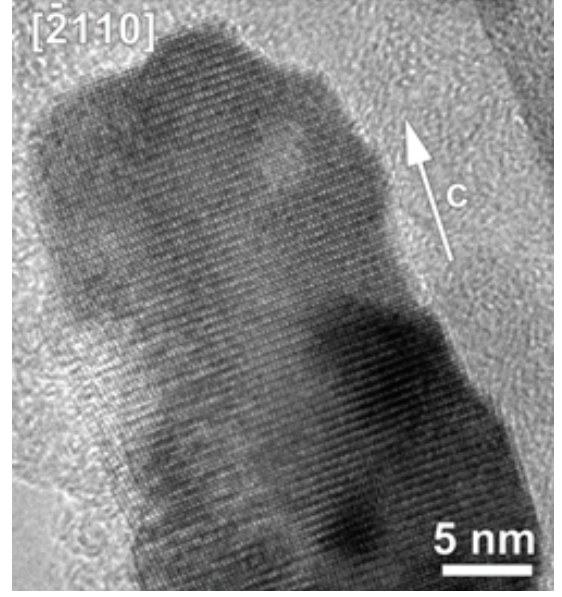

(b)

FIGURE 6: HR-TEM images of the $\mathrm{ZnO}: \mathrm{Al}$ nanorods obtained by stirring during a solvothermal treatment of $6 \mathrm{~h}$ at $200^{\circ} \mathrm{C}$ (top) and by a solvothermal treatment of $96 \mathrm{~h}$ at $200^{\circ} \mathrm{C}$ (bottom). The lighter patches are due to beam damage caused by the orientation process of the nanocrystals. The slightly different appearance at the left bottom side of the second crystal is Moiré caused by overlap with another nanocrystal.

decay times are different in almost one order of magnitude (4.6 $\mathrm{ms}$ against $24.8 \mathrm{~ms}$ ). If this difference is significant, it might suggest the existence of two different Al-positions of which the origin is still not clear. Avadhut et al. [33] reported about a core-shell structure with substitutional aluminium in the $\mathrm{ZnO}$ crystalline core and a shell or secondaryphase containing amorphous tetrahedral aluminium. However, an amorphous environment is not expected here, as the signals in the Al-NMR spectra are sharp. HR-TEM images indeed confirm that the nanocrystals consist of a single phase up to the edge of the crystals (Figure 6). No indications are observed consistent with an amorphous shell nor do the Fourier transforms of the images show any differences between the edge and the middle regions of the nanocrystals. Combining the information obtained by ${ }^{27} \mathrm{Al}-$ NMR spectroscopy and $T_{1}$-relaxometry suggests the key role importance of the ratio between substitutional and interstitial tetrahedral aluminium. While spectroscopy demonstrates a tetrahedral content of $31 \%$ versus $41 \%$ for $\mathrm{ZnO}: \mathrm{Al}$ nanorods obtained by solvothermal treatment at $200^{\circ} \mathrm{C}$ for $96 \mathrm{~h}$ and for $6 \mathrm{~h}$ with stirring, respectively, the $T_{1}$-results indicate a larger amount of substitutional $\mathrm{Al}$ for the former (77\% versus $66 \%$ ). Table 2 displays the ratio of substitutional/interstitial tetrahedral aluminium for the two ways of synthesis. Normalization to the interstitial tetrahedral fraction results in 3.4 substitutional aluminium ions for each interstitial aluminium ion for nanorods obtained by solvothermal treatment for $96 \mathrm{~h}$ at $200^{\circ} \mathrm{C}$ in contrast to only 1.9 for a solvothermal treatment for $6 \mathrm{~h}$ at $200^{\circ} \mathrm{C}$ with stirring. Based on this ratio, it becomes clear that a prolongation of the solvothermal reaction time yields the best conditions to enhance conductivity. Indeed, while substitutional aluminium improves the conductivity, interstitial aluminium has a negative effect on the conductivity.

\section{Conclusions}

By ${ }^{27} \mathrm{Al}-\mathrm{NMR}$ experiments, it is shown that a longer solvothermal treatment as well as stirring during the solvothermal 
TABLE 2: Combination of the information obtained by ${ }^{27} \mathrm{Al}-\mathrm{NMR}$ spectroscopy (tetrahedral content of $31 \%$ versus $41 \%$ for $\mathrm{ZnO}$ : $\mathrm{Al}$ nanorods obtained by solvothermal treatment at $200^{\circ} \mathrm{C}$ for $96 \mathrm{~h}$ and for $6 \mathrm{~h}$ with stirring, resp.) and $T_{1}$-relaxometry (77\% substitutional aluminium for the former versus $66 \%$ for the latter). Normalization to the interstitial tetrahedral fraction results in 3.4 substitutional aluminium ions for each interstitial aluminium ion for nanorods obtained by solvothermal treatment for $96 \mathrm{~h}$ at $200^{\circ} \mathrm{C}$ in contrast to only 1.9 for a solvothermal treatment for $6 \mathrm{~h}$ at $200^{\circ} \mathrm{C}$ with stirring.

\begin{tabular}{lccc}
\hline \multicolumn{2}{c}{$96 \mathrm{~h} @ 200^{\circ} \mathrm{C}$ without stirring } & & $6 \mathrm{~h} @ 200^{\circ} \mathrm{C}$ with stirring \\
$31 \%$ tetrahedral Al & 1 & Interstitial tetrahedral Al & $31 \%$ tetrahedral $\mathrm{Al}$ \\
\hline $23 \% \times 31 \%=7 \%$ & 3.4 & Substitutional tetrahedral Al & $34 \% \times 41 \%=14 \%$ \\
$77 \% \times 31 \%=24 \%$ & & $\mathbf{6 6} \% \times 41 \%=27 \%$ & 1 \\
\hline
\end{tabular}

treatment results in an increase of the tetrahedral aluminium fraction in the resulting $\mathrm{ZnO}$ nanocrystalline rods. Furthermore, the appearance of a plasmon absorption signal (FTIR spectra) due to the presence of free charge carriers and the significant increase in conductivity (microwave absorption measurements) for $\mathrm{ZnO}: \mathrm{Al}$ nanocrystals that were solvothermally treated for longer reaction times $(48 \mathrm{~h}$ and $96 \mathrm{~h}$ ) suggests an increase of the tetrahedral aluminium in substitutional positions. The lack of a plasmon absorption signal and of a significant increase in conductivity for the ZnO:Al nanocrystals prepared by stirring during a short solvothermal reaction time of $6 \mathrm{~h}$ suggests that the increase in the tetrahedral aluminium fraction is not associated with an increase in substitutional aluminium in these crystals. Additionally, the $T_{1}$ spin-lattice relaxation time behavior of the tetrahedral signal shows a $77 \%$ contribution of substitutional tetrahedral aluminium in the $\mathrm{ZnO}: \mathrm{Al}$ nanorods obtained by $96 \mathrm{~h}$ solvothermal treatment as compared to a $66 \%$ contribution of substitutional tetrahedral aluminium in the $\mathrm{ZnO}$ :Al nanorods obtained by stirring during the $6 \mathrm{~h}$ solvothermal treatment.

It can be concluded that the substitutional tetrahedral aluminium fraction can be successfully increased by extending the duration of the solvothermal treatment. The $\mathrm{ZnO}: \mathrm{Al}$ nanorods solvothermally treated for $96 \mathrm{~h}$ exhibited the largest proportion of substitutional tetrahedral aluminium, making this the most promising route for further studies. Furthermore, it is demonstrated that, by employing the unique combination of complementary techniques used in this study, the exact position of aluminium in the $\mathrm{ZnO}$ lattice can be determined, allowing to make predictions toward the best building blocks for transparent conductive layers.

\section{Conflict of Interests}

The authors declare that there is no conflict of interests regarding the publication of this paper.

\section{Acknowledgments}

The authors are indebted to G. Reekmans (UHasselt) for the ${ }^{27}$ Al-NMR measurements and B. Ruttens (UHasselt) for the X-ray diffraction measurements. The reported research was funded by the Research Foundation Flanders (FWO Vlaanderen), the Flemish Methusalem Nanoprogram, and the SOPPOM program of the Flemish Strategic Initiative for
Materials (SIM) and Interreg Vlaanderen Nederland, Solar Flare, under project no. IVA-VLANED-1.59.

\section{References}

[1] D. S. Ginley, H. Hosono, and D. C. Paine, Handbook of Transparent Conductors, Springer, New York, NY, USA, 2011.

[2] T. Minami, "Transparent conducting oxide semiconductors for transparent electrodes," Semiconductor Science and Technology, vol. 20, no. 4, article S35, 2005.

[3] H. Y. Liu, V. Avrutin, N. Izyumskaya, Ü. Özgr, and H. Morkoç, "Transparent conducting oxides for electrode applications in light emitting and absorbing devices," Superlattices and Microstructures, vol. 48, no. 5, pp. 458-484, 2010.

[4] Y. L. Liu, Y. F. Li, and H. B. Zeng, "ZnO-based transparent conductive thin films: doping, performance, and processing," Journal of Nanomaterials, vol. 2013, Article ID 196521, 9 pages, 2013.

[5] Z. H. Lu, J. X. Zhou, A. J. Wang, N. Wang, and X. N. Yang, "Synthesis of aluminium-doped $\mathrm{ZnO}$ nanocrystals with controllable morphology and enhanced electrical conductivity," Journal of Materials Chemistry, vol. 21, no. 12, pp. 4161-4167, 2011.

[6] T. V. Thu and S. Maenosono, "Synthesis of high-quality Aldoped ZnO nanoink," Journal of Applied Physics, vol. 107, no. 1, Article ID 014308, 2010.

[7] D. V. Talapin, J.-S. Lee, M. V. Kovalenko, and E. V. Shevchenko, "Prospects of colloidal nanocrystals for electronic and optoelectronic applications," Chemical Reviews, vol. 110, no. 1, pp. 389458, 2010.

[8] B. Nasr, S. Dasgupta, D. Wang, N. Mechau, R. Kruk, and H. Hahn, "Electrical resistivity of nanocrystalline Al-doped zinc oxide films as a function of $\mathrm{Al}$ content and the degree of its segregation at the grain boundaries," Journal of Applied Physics, vol. 108, no. 10, Article ID 103721, 2010.

[9] X. F. Han, K. Han, and M. Tao, "Electrodeposition of group-IIIA doped $\mathrm{ZnO}$ as a transparent conductive oxide," in Photovoltaics for the 21st Century 5, M. Tao, P. Chang, K. Kakimoto et al., Eds., vol. 25, pp. 93-102, 2010.

[10] D.-J. Lee, J.-Y. Kwon, S.-H. Kim, H.-M. Kim, and K.-B. Kim, "Effect of Al distribution on carrier generation of atomic layer deposited Al-doped ZnO films," Journal of the Electrochemical Society, vol. 158, no. 5, pp. D277-D281, 2011.

[11] X. H. Wang, R. B. Li, and D. H. Fan, "Study on synthesis and optical properties of Al-doped $\mathrm{ZnO}$ hierarchical nanostructures," AIP Advances, vol. 1, no. 1, Article ID 012107, 2011.

[12] E. Vasile, R. Plugaru, S. Mihaiu, and A. Toader, "Study of microstructure and elemental micro-composition of $\mathrm{ZnO}: \mathrm{Al}$ 
thin films by scanning and high resolution transmission electron microscopy and energy dispersive X-ray spectroscopy," Romanian Journal of Information Science and Technology, vol. 14, no. 4, pp. 346-355, 2011.

[13] Y. Zhang, Y. Yang, J. Zhao et al., "Optical and electrical properties of aluminum-doped zinc oxide nanoparticles," Journal of Materials Science, vol. 46, no. 3, pp. 774-780, 2011.

[14] H. Serier, A. Demourgues, J. Majimel, and M. Gaudon, "Infrared absorptive properties of Al-doped $\mathrm{ZnO}$ divided powder," Journal of Solid State Chemistry, vol. 184, no. 6, pp. 1523-1529, 2011.

[15] K. Elen, A. Kelchtermans, H. van den Rul et al., "Comparison of two novel solution-based routes for the synthesis of equiaxed zno nanoparticles," Journal of Nanomaterials, vol. 2011, Article ID 390621, 6 pages, 2011.

[16] H. Damm, A. Kelchtermans, A. Bertha et al., "Thermal decomposition synthesis of Al-doped $\mathrm{ZnO}$ nanoparticles: an in-depth study," RSC Advances, vol. 3, no. 45, pp. 23745-23754, 2013.

[17] D. Nie, T. Xue, Y. Zhang, and X. Li, "Synthesis and structure analysis of aluminum doped zinc oxide powders," Science in China Series B: Chemistry, vol. 51, no. 9, pp. 823-828, 2008.

[18] H. Serier, M. Gaudon, and M. Ménétrier, "Al-doped ZnO powdered materials: Al solubility limit and IR absorption properties," Solid State Sciences, vol. 11, no. 7, pp. 1192-1197, 2009.

[19] T. K. Gupta, "Microstructural engineering through donor and acceptor doping in the grain and grain boundary of a polycrystalline semiconducting ceramic," Journal of Materials Research, vol. 7, no. 12, pp. 3280-3295, 1992.

[20] T. Kemmitt, B. Ingham, and R. Linklater, "Optimization of solgel-formed $\mathrm{ZnO}: \mathrm{Al}$ processing parameters by observation of dopant ion location using solid-state ${ }^{27} \mathrm{Al}$ NMR spectrometry," The Journal of Physical Chemistry C, vol. 115, no. 30, pp. 1503115039, 2011.

[21] J. P. Kar, S. Kim, B. Shin et al., "Influence of sputtering pressure on morphological, mechanical and electrical properties of Aldoped ZnO films," Solid-State Electronics, vol. 54, no. 11, pp. 1447-1450, 2010.

[22] S. Mridha and D. Basak, "Aluminium doped ZnO films: electrical, optical and photoresponse studies," Journal of Physics D: Applied Physics, vol. 40, no. 22, pp. 6902-6907, 2007.

[23] A. Kelchtermans, K. Elen, K. Schellens et al., "Relation between synthesis conditions, dopant position and charge carriers in aluminium-doped $\mathrm{ZnO}$ nanoparticles," RSC Advances, vol. 3, no. 35, pp. 15254-15262, 2013.

[24] R. A. Waldron, The Theory of Waveguides and Cavities, Maclaren \& Sons Ltd, London, UK, 1967.

[25] D. Slocombe, A. Porch, E. Bustarret, and O. A. Williams, "Microwave properties of nanodiamond particles," Applied Physics Letters, vol. 102, no. 24, Article ID 244102, 2013.

[26] K. J. D. MacKenzie and M. E. Smith, Multinuclear Solid-State NMR of Inorganic Materials, Elsevier, New York, NY, USA, 2002.

[27] M. Kanehara, H. Koike, T. Yoshinaga, and T. Teranishi, "Indium tin oxide nanoparticles with compositionally tunable surface plasmon resonance frequencies in the near-IR region," Journal of the American Chemical Society, vol. 131, no. 49, pp. 1773617737, 2009.

[28] T. Wang and P. V. Radovanovic, "Free electron concentration in colloidal indium tin oxide nanocrystals determined by their size and structure," Journal of Physical Chemistry C, vol. 115, no. 2, pp. 406-413, 2011.

[29] M. Jullien, D. Horwat, F. Manzeh et al., "Influence of the nanoscale structural features on the properties and electronic structure of Al-doped $\mathrm{ZnO}$ thin films: an X-ray Absorption Study," Solar Energy Materials and Solar Cells, vol. 95, no. 8, pp. 2341-2346, 2011.

[30] J. N. Duenow, T. A. Gessert, D. M. Wood, B. Egaas, R. Noufi, and T. J. Coutts, "Investigation of $\mathrm{ZnO}$ : Al doping level and deposition temperature effects on CIGS solar cell performance," in Thin-Film Compound Semiconductor Photovoltaics, T. Gessert, K. Durose, C. Heske, S. Marsillac, and T. Wada, Eds., vol. 1012, pp. 15-20, 2007.

[31] P. Gondoni, M. Ghidelli, F. Di Fonzo et al., "Structuredependent optical and electrical transport properties of nanostructured Al-doped ZnO," Nanotechnology, vol. 23, no. 36, Article ID 365706, 2012.

[32] J. F. Stebbins, "Aluminum substitution in rutile titanium dioxide: new constraints from high-resolution ${ }^{27} \mathrm{Al} \mathrm{NMR,"} \mathrm{Chem-}$ istry of Materials, vol. 19, no. 7, pp. 1862-1869, 2007.

[33] Y. S. Avadhut, J. Weber, E. Hammarberg, C. Feldmann, and J. Schmedt Auf Der Günne, "Structural investigation of aluminium doped $\mathrm{ZnO}$ nanoparticles by solid-state NMR spectroscopy," Physical Chemistry Chemical Physics, vol. 14, no. 33, pp. 11610-11625, 2012. 



Submit your manuscripts at http://www.hindawi.com


\section{The Scientific World Journal}
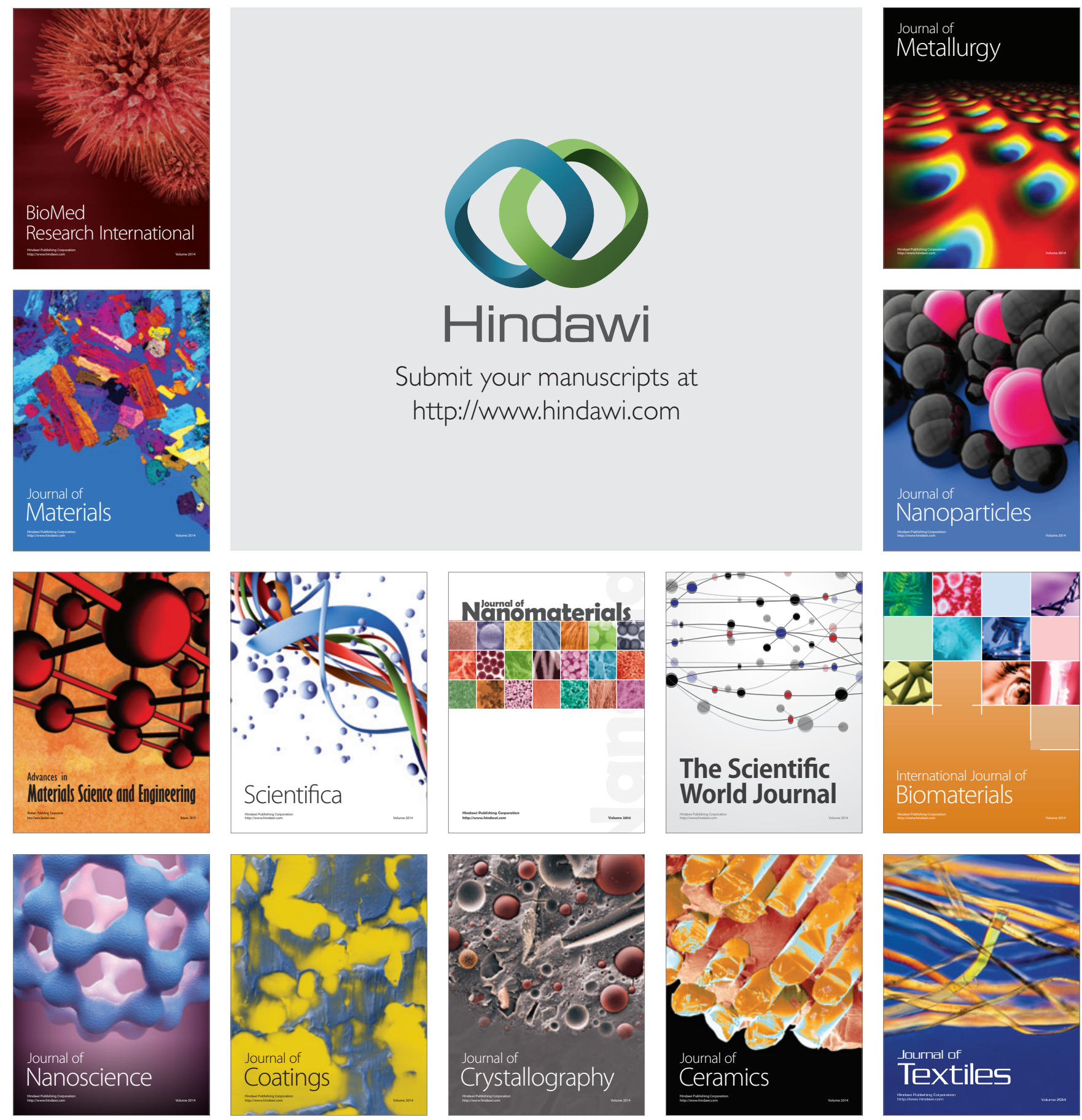